\title{
Por uma arqueologia do corpo: representação, imagem e educação ${ }^{1}$
}

\section{For an archeology of the body: representation, image, and education}

Gleyse, Jacques (2018). A instrumentalização do corpo: uma arqueologia da racionalização instrumental do corpo, da Idade Clássica à época hipermoderna (A. A. Lima Neto, C. E. A. Moraes \& F. L. S. Teixeira, trads., 1a ed.). São Paulo: LiberArs.

(i) Universidade do Estado do Pará - Uepa, Belém, PA, Brasil. https://orcid.org/0000-0003-1588-7305, martagenu@gmail.com.

(ii) Universidade do Estado do Pará - Uepa, Belém, PA, Brasil. https://orcid.org/0000-0002-31806897, teressa2101@gmail.com.

A obra $A$ instrumentalização do corpo: uma arqueologia da racionalização instrumental do corpo, da Idade Clássica à época hipermoderna, de Jacques Gleyse (2018), nasceu de sua tese, defendida há mais de duas décadas, e se mantém atual em tempos de racionalização, sensibilização e instrumentalização do corpo. O livro foi publicado originalmente em 1997 e ganhou tradução e primeira edição fora da França em 2018, pela Editora LiberArs, em escrita fidedigna e criativa de Avelino Aldo de Lima Neto, Cláudia Emília Aguiar Moraes e Fábio Luís Santos Teixeira, todos orientandos de Gleyse e, além disso, viventes de sua produção e aventura no mundo.

\footnotetext{
${ }^{1}$ Normalização, preparação e revisão textual: Mônica Silva (Tikinet) - revisao@tikinet.com.br 


\section{pro.posıções \\ $e$-ISSN 1980-6248}

http://dx.doi.org/10.1590/1980-6248-2019-0103

Com prefácio escrito pela professora Carmen Lúcia Soares, livre-docente da Universidade Estadual de Campinas (Unicamp), a obra enfatiza o projeto ambicioso que perpassa quatro séculos de discursos, tomando o corpo como objeto/sujeito em constante transformação, e faz, ainda, um mapeamento da aventura humana e de sua possível educação. O livro está organizado em seis partes e vinte capítulos, além de um posfácio escrito pelo próprio autor, que atualiza a proposta e escreve especialmente para a edição brasileira, acentuando que já se passaram mais de vinte anos desde a primeira edição e que as teorias do transumanismo têm aumentado, sendo essa tradução uma oportunidade para ampliar o trabalho realizado em 1997 em relação à instrumentalização do corpo e à sua manufatura racional, em todos os processos descritos no livro em sua versão original.

Essa riquíssima obra apresenta o longo período de estudo e investigação do autor a partir de livros, imagens, atlas, artigos e da leitura de vários estudiosos e cientistas, entre eles: Michel Foucault, André Leroi-Gourhan, Francis Bacon, Friedrich Nietzsche e Andreas Vesalius. Gleyse dialoga com eles para construir uma arqueologia do corpo autoral e precisa para compreender sua instrumentalização, visão construída socialmente e que se torna instrumento do próprio humano. Com os estudos arqueológicos e da arqueologia dos discursos, Gleyse se aproxima da visão foucaultiana e apresenta um eixo epistemológico voltado a uma análise histórico-crítica do conhecimento. Por isso, torna-se referência e interlocutor para percepções das rupturas arqueológicas sobre a educação do físico, da imagem e das práticas corporais, analisadas detalhadamente, que fundamentam o conjunto de sistemas de instrumentalização do corpo criado pelo autor.

A primeira parte do livro é composta pelos capítulos I e II, e apresenta uma arqueologia da arqueologia dos discursos, em que Gleyse reflete sobre o conhecimento numa perspectiva dialética e trata das lógicas do pensamento idealismo ou materialismo para apresentar as duas visões centrais sobre a relação entre homem e natureza presentes em Karl Marx. Com Nietzsche, considera as transformações do real como tributárias da materialidade. A percepção desenvolvida no capítulo I dá destaque para Marx, posto que o homem, a natureza e o trabalho são objetos de estudo marxista, segundo o qual o homem, possuidor de cultura, modifica o próprio ser humano natural, ressaltando que é pelo trabalho que se constitui a condição de existência desse homem. O capítulo ainda nos apresenta a visão antropológica de André LeroiGourhan, que traz fatos importantes sobre a definição da técnica como elemento principal para 


\section{pro.posições}

http://dx.doi.org/10.1590/1980-6248-2019-0103

$e$-ISSN 1980-6248

uma noção da evolução humana. Gleyse defende a importância dessas colocações para a arqueologia da racionalização instrumental do corpo.

No capítulo II, Gleyse dialoga com os autores Francis Bacon, René Descartes, Immanuel Kant, Wilhelm Dilthey, Michel Foucault e Edmund Husserl sobre a arqueologia da instrumentalização do corpo, reforçando a discussão sobre a arqueologia dos discursos e descrevendo uma história parcial da epistemologia. O autor utiliza-se de Michel Foucault para fazer uma reflexão epistemológica, filosófica e histórica dos processos arqueológicos de instrumentalização do corpo. O capítulo traz um caminho do pensamento para discussões sobre ciências da racionalização, ciência do espírito e o nascimento da tecnocientificização do mundo moderno, onde nascerá, especificamente, a instrumentalização do corpo. Gleyse ainda explica que a ginástica racional, nascida nos primórdios da modernidade, é a primeira instrumentalização do movimento humano que substituirá um corpo de experiência por um corpo de experimentação, sendo, assim, um corpo exposto a teorizações abstratas de movimentos e consequentemente manipulado.

A partir da segunda parte do livro, iniciam-se os discursos sobre a criação do homem ou, como o próprio autor intitula, sobre "artesãos e fabricantes do corpo". Gleyse faz uma análise iconográfica de imagens que serão representações fundamentais da análise na qual o corpo - representado nas obras de arte As meninas (Diego Velásquez), Paisagem Pastoral com um moinho (Claude Lorrain), A Dança do Camponês (Pieter Bruegel), Os quatros evangelistas e O rei bebe (Jacob Jordaens), e $A$ bela jardineira (Rafael Sanzio) - é percebido de um modo completamente diferente entre o começo e o final da Idade Clássica. A descentralização, as técnicas de navegação, a tecnologia de localização, a Reforma Protestante e a anatomia construirão a maior ruptura da episteme que fundará a modernidade. Gleyse faz a análise da corporeidade dialogando com Foucault - e de representações de mecanização do homem, quando nascerá o corpo a ser educado, um simples objeto da ginástica e da anatomia.

O capítulo $\mathrm{V}$ prossegue com a análise iconográfica do atlas anatômico de André Vesalius, no qual são apresentadas várias imagens que, quando analisadas, contribuem para a discussão sobre a fabricação de corpos, sua instrumentalização e manufatura - por isso Vesalius é tomado como referência, uma vez que é o primeiro a manufaturar o corpo humano. Ainda nesse capítulo, Gleyse discorre que a instrumentalização manufatureira do movimento, com a ginástica moderna e a educação física, nas concepções galênicas, faz nascer uma fisiologia e uma 


\section{pro.posıções}

$e$-ISSN 1980-6248

anatomia nas quais o ser humano desaparece e o seu corpo se converte em um objeto de estudo e manipulação para técnicas produzidas pelo próprio ser humano.

$\mathrm{Na}$ terceira parte do livro, nos capítulos VI e VII, o autor apresenta a manufatura das coisas e do corpo. A mudança fundamental entre Mercurialis, Galileu e Descartes organiza uma discussão sobre a precisão matemática aplicada às coisas e ao corpo. Nesse sentido, existe uma padronização desse corpo que é voltado para a indústria, e há também a utilização de ferramentas, quando o corpo não suporta carregar um peso, que são criadas para que ele possa realizar seu trabalho. O corpo passa a ser manufaturado, e essa manufatura torna-se, então, o traço mais característico de um isomorfismo arqueológico. O ser humano está submetido a normas de comportamento, à padronização do corpo para sua utilização, agora com ajuda das ciências exatas, pois surge a geometrização da mecânica humana, a primeira racionalização instrumental, tomando por base o modelo das mecânicas galileanas.

Ainda na terceira parte, entre os capítulos VIII, IX e X, Gleyse apresenta movimentos na episteme e mudanças na instrumentalização do corpo. Uma ruptura na episteme será crucial para o modelamento das práticas corporais e ginásticas. O autor Nicolas Andry, médico francês que discute sobre o corpo, forma uma espécie de paradigma da instrumentalização manufatureira do corpo, sendo seu debate voltado às crianças e às deformidades causadas em seu corpo antes ou depois do nascimento, seja por suas mães, que não cuidaram bem do corpo antes de a criança nascer, ou pelas babás, que são representadas pelo autor como pessoas de humanidade inferior, já que, para Andry, o instinto e as ações animais do ser humano já não são tão necessários - por isso o autor apresenta técnicas para melhorar a postura na hora de sentar e até de trabalhar.

Já na Revolução Francesa, o corpo, "que até então parecia ser um microcosmo aceitável" (Gleyse, 2018, p. 194), começa então a ser aperfeiçoado, assim como nos Jogos Olímpicos, que serão retomados em 1712, com a prática de atividades que seriam (em teoria) gratuitas. A teoria da termodinâmica também é utilizada para o aperfeiçoamento manufatureiro do corpo. Essa instrumentalização energética começa a delinear o que teoricamente se dá pela racionalização instrumental do corpo manufatureiro.

Então, no final desses três capítulos, Gleyse aborda que, no fim do século XVIII e no início do século XIX, o homem fabricado pelas ginásticas racionais de Borelli desde a infância tem como perspectiva valorizar o aperfeiçoamento do trabalho humano, seu rendimento e sua 


\section{pro.posıções}

$e$-ISSN 1980-6248

eficácia. A energia corporal e o rendimento tornam-se mecanismos cardinais, ordenando o conjunto do espaço discursivo e fundando um método. Esse excerto revela, agora, a proximidade de novos recordes esportivos. Os vestígios da operadora da energia artificial e filha da máquina a vapor vão racionalizar instrumentalmente o invisível do corpo, criando conceitos de rendimento e modelamento do corpo.

$\mathrm{Na}$ quarta parte do livro, Gleyse trata dos discursos racionais dos séculos XIX e XX, com as teorias da termodinâmica, a calorimetria, a máquina a vapor, e do desempenho do homem energético, com as ginásticas de quarto. A fábrica de energia artificial conduz a instrumentalização racional do corpo para a necessidade de aumentar o rendimento de tudo. Quando se parte da perspectiva da entrada de um sistema mecânico de rendimento energético, junto com a máquina a vapor e o combustível, irá se construir um novo sistema metafórico de crenças (teorias) científicas para o funcionamento do corpo humano como máquina energética. Gleyse explica, também, que os espaços discursivos concernentes à instrumentalização racional do corpo passam por uma profunda reorganização, pois o aperfeiçoamento e o rendimento produtivo, tanto no esporte quanto nas relações diretas entre homem e matéria, fazem com que o homem tenha mais poder sobre o corpo.

No capítulo XIII, aborda-se como as ferramentas para instrumentalizar o corpo vão ser formuladas por médicos ginastas. Os procedimentos de modelação das ginásticas racionais buscam reforçar a relevância do instrumento e justificam seu uso para sustentar um discurso sem palavras e silencioso da instrumentalização do corpo. Esse discurso se alastra, se ramifica, e percebe-se sua aceitação e o desenvolvimento do uso do aparelho industrial padronizado, que irá substituir a obra artesã e única, anteriormente mencionada por Gleyse. A ginástica individual de Pichery deverá ser transmitida, e a educação física participará de um sistema que justificará os discursos de instrumentalização do corpo. No século XIX, o corpo tornou-se instrumentalizado e racionalizado nos aspectos energéticos, calóricos e carbônicos, e passou a ser uma espécie de carvão que vai ser consumido pela máquina a vapor.

No final do livro, na quinta e sexta parte, Gleyse continua o raciocínio de uma instrumentalização racional do corpo moderno e hipermoderno, em cujas práticas de educação o prazer lúdico não está presente. George Demeny, precursor da educação física estatal na França, apresenta a perspectiva de um homem mais humano, sendo a dominação racional da natureza, seja ela interna ou externa, um ponto crucial da visão moderna do ser humano. $\mathrm{O}$ 


\section{pro.posições \\ $e$-ISSN 1980-6248}

processo de prazeres do corpo, em um campo restrito, permitiu um esclarecimento apropriado no que se refere ao corpo moderno, que é um corpo racional e um pouco instrumentalizado para a produção, produtor de trabalho e de rendimento. Já no início do século XX, a reabilitação de um possível prazer corporal lúdico questiona a ordem do discurso, pois trata-se de uma nova interiorização da regularização do corpo, como também de uma ruptura radical da ordem moderna.

Gleyse finaliza seu livro explicando que a instrumentalização racional do corpo e os discursos mantidos sobre ele permitem identificar índices analíticos do corpo em determinados períodos, fortalecendo o discurso de uma arqueologia da racionalização instrumental do corpo, que está sempre em diálogo com o modo de produção consequente de um mundo social, político e educativo. Uma arqueologia humana do corpo revela modalidades e crenças da educação física, filosofia, anatomia e antropologia, e dessa combinação do todo que se compõe o corpo, que ainda continua por ser a sua instrumentalização.

\section{Referência}

Gleyse, J. (2018). A instrumentalização do corpo: uma arqueologia da racionalização instrumental do corpo, da Idade Média à época hipermoderna (A. A. Lima Neto, C. E. A. Moraes \& F. L. S. Teixeira, trads., 1a ed.). São Paulo: LiberArs.

Submetido à avaliação em 30 de agosto de 2019; aceito para publicação em 2 de outubro de 2019. 